\title{
Network Education Capital as a Specific Digital Economy Asset
}

\author{
Natalia A. Yegina ${ }^{1 *}$, Elena S. Zemskova ${ }^{1}$, and Natalia Sh. Vatolkina ${ }^{2}$ \\ ${ }^{1}$ Ogarev Mordovia State University, Bolshevist str., 68, 430005, Saransk, Russia \\ ${ }^{2}$ Bauman Moscow State Technical University, 2nd Baumanskaya str., 5/1, 105005, Moscow, Russia
}

\begin{abstract}
In the context of the global digital transformation, the most important factors determining socio-economic progress are the specific properties of human capital that are inherent only in the digital economy. In the new conditions, the role of integratively distributed network interaction of participants of global, national, corporate and social networks in the training of highly qualified specialists with new information and network skills and competencies is growing, a new form of human capital is emerging - network education capital (network education capital). On the basis of an interdisciplinary approach (economics, sociology, psychology, pedagogy, etc.), positive externalities are described that arise as a result of the inclusion of education in network communication processes. One of the main specific features of modern education is the departure from its linearity and verticality. It is shown that the network formation capital acquires the properties of a specific asset that brings a quasi-rent, and acts as a social elevator only if the involvement of more entities in the network increases
\end{abstract}

\section{Introduction}

The development of the global computer network has opened up new prospects for the evolutionary improvement of the world and Russian scientific and educational system. Evolution, as we know, assumes that the process of natural selection leaves the most viable and adaptive forms. By adaptability, in this case, we mean the ability to acquire characteristics that are important for survival and to eliminate those that absorb resources, but do not produce results.

Due to the open borders provided by the digital environment, the labor market is no longer tied to a specific geographical territory, making the bearer of competitive competencies (in other words, the most adaptive individual) in demand in the global human capital market. And the value of human capital, as well as any good in a perfect market, depends on the totality of benefits that the specialist can offer to interested actors.

Networks are becoming a specific asset of the digital economy that can, due to the availability of educational resources and synchronous involvement in the education process of a large number of participants (each participant not only receives information, but also becomes its source), serve as a so called social elevator for carriers of competitive human

* Corresponding author: avantacom@ mail.ru 
capital. In this context, we propose to understand the network education capital as a set of properties of human capital that appear due to the use of digital economy opportunities, the acceleration effect of which becomes the most important source of intellectual potential formation and the driver of innovative development of subjects. The use of digital technologies makes it possible to form an ecosystem adapted to the needs of both a specific individual who determines the vector of his development, and to meet the needs of national economies focused on obtaining an additional effect [1].

\section{Evolution of Understanding the Education Capital}

The system of traditional education, which involves vertical learning from teacher to student, was formed during a period of scarcity and high cost of information sources (especially books). The centers of education were often monasteries or parochial schools, where knowledge was presented in the context of the dominant religion, which excluded the emergence of points of view which could offer alternative to Church dogmas. The strict limitation of the offer of education services made it available only to the wealthy strata of the population (the aristocracy and the bourgeoisie). In itself, learning to read and write and knowledge of other sciences meant belonging to the leisure class, since education was an indicator of wealth and idleness, but not an asset capable of generating income.

The problem of scaling up knowledge in pre-industrial society made the family one of the training institutions where information was transmitted in verbal form or in the form of teaching specific skills from the older generation to the younger. This led to the formation of dynasties, but did not take into account the propensities of students to certain types of activity: the younger generation was held hostage to the existing specialization, which was very difficult to change. The exchange of knowledge, experience and information between representatives of various social groups and professions was episodic and was the exception rather than the rule. In today's terms, there was no interdisciplinarity.

The situation changed somewhat with the invention of the printing press and the decline in the cost of books. However, education was still the prerogative of the elites, since books were printed in a dead Latin language unknown to most of people. This lack of education significantly hindered socio-economic progress, and many scientific research was not needed because there was a huge gap between producers and consumers of knowledge.

The real revolution in terms of the application and dissemination of knowledge and scientific ideas occurred in the age of Enlightenment with the rejection of exclusively religious world perception and the publication of books in Latin. Its adherents (J. Locke, D. Diderot, P. Holbach, J.-J. Rousseau) argued that education should be accessible to the majority and have practical benefits for people. That is, the attitude to education and science is changing - it is no longer just an indicator of wealth, it is knowledge that should be useful, should become an asset that contributes to development!

It is worth noting that economists have always been and continue to be interested in the question raised by A. Smith in the title of his fundamental research - about the nature and causes of the wealth of nations, which, in fact, is the question of finding sources of economic progress. And if the research of economists before the beginning of the XX century. conditionally focused on the dominant value of a single asset (factor of production) - labor, land, capital, then an empirical analysis of the results of the industrial revolution made it possible to assert that the most important causes of economic development at the present stage are human creativity, as well as scientific and technical progress (Y. Schumpeter, N. Kondratev). These theories appeared as a prerequisite for the model proposed by R. Solow, who argued that scientific and technological progress is the only factor of long-term economic growth [2]. However, progress does not exist by itself, because it is in a dialectical relationship with its bearer - a man, a deep awareness of this 
dependence led to the formulation of the theory of human capital $[3 ; 4]$ and shifted the focus from the analysis of traditional factors of production in achieving economic progress to the role of knowledge [5;6].

At the same time, G. Bakker attaches special importance to specific human capital, which, in contrast to general human capital (the skills necessary to perform almost any work - the ability to speak, count, walk, etc.), can bring additional income (quasi-resident) only under certain conditions of employment. That is, a specific asset is something that can bring quasi-rent and ensure the achievement of an additional effect only if it is "properly" used. For example, a person may have a musical talent, but if there are no conditions for its detection (in his remote village there is simply no musical school, and parents do not have the competence to diagnose the child's abilities due to their own lack of education), then the specificity does not manifest itself and the talent is "buried in the ground". From this point of view, the potential of the digital economy makes it possible to diagnose human abilities even in those localities where there are no physical educational institutions, and the person in turn uses the opportunities of social dynamics, which are part of the properties of a network society.

Further development and complication of post-industrial society, changes in the nature of economic activity, in the content of labor, based on highly intellectual human capital, science as a direct productive force, was embodied in the terms "new economy", "information society", "digital economy" [7;8;9]. The critical reinterpretation of postindustrial society theories in conjunction with the assumptions of the Solow model led to the emergence in the mid-1980 the "new growth theory" that explains economic growth by innate factors, in particular the accumulation of knowledge [10; 11]. Thus, education has established itself as a determinant of economic growth and a specific asset that can bring additional income.

At the same time, it is important to note that education creates a kind of effect of increasing returns on capital (acceleration effect), which is greater if the more subjects are involved in the process. The concept of the accelerated effect of collective knowledge and actions has been studied in the works of philosophers, psychologists and psychiatrists, sociologists $[12 ; 13 ; 14 ; 15]$. Moreover, initially, networks were understood as a certain social reality that can identify and accumulate collective experience created by the flow of mutual actions and the transfer of utility between communicators, whether it is a family, a firm or a society as a whole $[16 ; 17 ; 18 ; 19 ; 20]$.

Digital transformation, accompanied by the rapid spread of new methods of communication, the use of network services by various social groups affected the ways of translating the accumulated knowledge, where the classical " vertical "education gives way to "horizontal" (training on the "equal to equal "model") [21;22; 23; 24]. For such a model, it is not just the diploma acquired within formal educational institutions that is important, but the ability to search, process, turn into an asset and transfer the knowledge obtained. The modern capital of education is a "constructor" of relevant content for a particular situation, a kind of web of knowledge, woven by many network participants [25].

\section{The Development of Network Education Capital}

The development of ideas of connectivism, understood as open educational resources in combination with the network organization of interaction of participants [26], indicates that learning is a process of linking "specialized sources of information", i.e. the process of building a network where educational analytics can be used to unite weaker participants with stronger ones, to help students with similar interests to find each other and a mentor. Thanks to the level of development to which modern information systems have come to support the scientific and educational community, it is possible to use the method of 
training projects as a pass to the knowledge-sharing communities. The developing possibilities of joint activity, its positive impact on the motivational, intellectual, communicative potential of the student, his orientation not to raise awareness, but to the ability to solve problems have been studied by domestic teachers [27, 28, 29].

Today, traditional methods of education are supplemented by new methods of education based on the use of the Internet, network technologies and electronic and telecommunication means. Network distance education, mass open online courses, teleeducation, etc., based on Internet technologies, perform a number of new functions and involve the implementation of certain principles, among which the principle of distributed cooperation, integration, and entry into the global network of scientific and educational space is important. In the new conditions, such new properties of human capital as network multifunctionality, network openness, network communication skills, network flexibility, and network mobility are of paramount importance.

A modern specialist, who are the carriers of human capital, should have the skills and competencies of network interaction with various structures: with network state structures (e-government), with network business structures (e-business, innovative firms, offshore programming) and with social networks. A new feature of human capital in the digital economy is system-network thinking, network continuous education and self-education.

Undoubtedly, in these conditions, it is necessary to reconsider the place of the University in the system of continuing education, to expand the understanding of the forms and methods of organization of education.

E-learning, networking and online education services are essential elements for the development of the digital economy under the influence of various factors [30]:

- technologies that provide new tools and technologies for learning in a co-temporal digital environment;

- social, including the need of society for a new quality of educational services aimed at expanding access to education, as well as the individual needs;

- economic, which is that education has always been an important endogenous factor of economic growth; [31].

- institutional when e-learning becomes the basis for building networks and partnerships

Using the opportunities of the digital economy in the field of education has the potential to increase the competitiveness of the national economy due to the accelerated effect of the transformation of the traditional education system into a highly intellectual network that provides for the neutralization of externalities provoked by the explotation of extensive growth factors.

Thus, the cross-scientific nature of the study of human capital has shown the need for a systematic approach that allows us to justify a new form of human capital in the era of digital transformation - the network education capital. Technology and tools of the digital economy become unique factors that will allow to fully create accelerative effect of education capital and to use the diversity of the network effects of education for formation of human capital and socio-economic development of countries, their social transformation.

It is obvious that the currently formed institutions of joint network activity have the characteristics of a specific asset and, contributing to the universal interconnectedness of subjects and objects of educational activity, have a significant impact on the formation of the network education capital through socio-cultural and economic factors, computerization and digitalization, global monitoring of the activities of network participants. At the same time, the number of topical interdisciplinary studies in the field of the socio-economic potential of network education and legislative and technological limitations of this process is still scarce [32]. 


\section{Conclusion}

In order to develop the methodological basis of the theory of human capital, it is necessary to develop a new scientific concept of "network education capital", the accelerated effect of which is the most important source of intellectual potential and the driver of innovative development of subjects at all levels (countries, regions, companies, individuals). In general, the authors associate the prospects of the new scientific concept for science and practice with the development of an interdisciplinary approach to the study of the phenomenon of "human capital".

From the position of psychological-pedagogical and actor-network approaches to the analysis of joint network activity, a methodological approach to the construction of an individual educational trajectory of a student (schoolboy, student, employee) in the system of continuous education can be developed and proposed.

The comparative legal approach to the study will allow to analyze the methodological, regulatory and legal tools that determine the nature of the institutional environment for the implementation of network continuing education. To this end, it is necessary to monitor the economic and legal compliance of the existing institutional environment of education, its elements, participants and processes with the requirements of educational ecosystems of the new generation. Obviously, serious problems may arise here, since most organizations impose competence-based requirements on their employees (which very often do not correlate with formal education), and the regulatory authorities check the presence of formal education. Due to the fact that competence monitoring is a much more complex and expensive procedure associated with the search for an expert who can assess the relevance of the specific human capital of the occupied position, effective institutions in this area have not yet been formed.

Active developments in this direction will solve the problem that actually has the status of a challenge - the formation and development of human capital, which has a variety of network and digital competencies at various levels: at the global level, at the state level (egovernment), at the corporate (private companies) and at the individual social (social networks), in order to ensure innovative economic growth in the conditions of high dynamism of the digital economy and global hypercompetition.

\section{References}

1. N.A. Yegina, E.S. Zemskova, V.A. Gorin, D.I. Stepanova, Applying consumer behavior theory in the context of the digital transformation of the economy, International journal of supply chain management, Vol. 8, No. 3, pp. 341-347 (2019)

2. R.A. Solow, Contribution to the Theory of Economic Growth, The Quarterly Journal of Economics, Vol. 70, No. 1, February 1956, pp. 65-94 (1956)

3. W. Schultz Theodore, Capital Formation by Education, Journal of Political Economy 68, no. 6, December 1960, pp. 571-583 (1960)

4. G. Becker, Investment in Human Capital: A Theoretical Analysis, Journal of Political Economy 70, no. 5, Part 2, October1962, pp. 9-49 (1962)

5. J.C. Galbraith, New Industrial Society, Moscow, Progress, p. 149 (1969)

6. G. Murdal, Modern problems of the "third world", Moscow: Progress, p. 767 (1972)

7. D. Bell, Future post-industrial society, Experience of social forecasting, Moscow: Academia, p. 944 (2004)

8. E. Masuda, Information Society as Post-Industrial Society, Moscow: Academia (1997)

9. E. Toffler, Tret'ya volna [The Third Wave], Moskow, AST, p. 784 (2004) 
10. P. Romer, Increasing Returns and Long-Run Growth, The Journal of Political Economy, Vol. 94, No. 5, October 1986, pp. 1002-1037 (1986)

11. R. Lucas, On the Mechanics of Economic Development Journal of Monetary, Economics, Elsevier, vol. 22(1), pp. 3-42 (1988)

12. J. Moreno, Who Shall Survivel? Foundations of Sociometry, Group Psychotherapy and Sociodrama, Beacon (NY): Beacon House 1953, Wash., DC (1934)

13. M. Granovetter, Economic Action and Social Structure: The Problem of Embeddedness, American Journal of Sociology, November 1985, Vol. 91, pp. 481-510 (1985)

14. P. Dubini, H. Aldrich, Personal and extended networks are central to the entrepreneurial process, Journal of Business Venturing, 6, pp. 305-313 (1991)

15. C. Jones, W. Hesterly, S.A. Borgatti, General Theory of Network Governance: Exchange Conditions and Social Mechanisms (1997)

16. G.A. Becker, Treatise on the Family, Cambridge,London: Harvard University Press (1991)

17. A. Alchian Armen, H. Demsetz, Production, Information Costs, and Economic Organization, The American Economic Review, Vol. 62, No. 5, December 1972, pp. 777-795 (1972)

18. P. Bourdieu, Espace Social et Pouvoir Symbolique, Paris: Editions de Minuit, 1987.

19. M. Castels, Information Epoche: economy, society and culture.., Moscow: Higher School of Economics Publishing House, p. 608 (2000)

20. E. Rinert, How Rich Countries got Rich...And Why Poor Countries Stay Poor, Moscow: Higher School of Economics Publishing House, p. 437 (2011)

21. M.S. Knowles, The Modern Practice of Adult Education: from Pedagogy to Andragogy (Rev. Ed.), M.S. Knowles, N.Y.: Association Press, p. 400 (1980)

22. M.-J. Eisen, Peer-Based Learning: A New-Old Alternative to Professional Development, Adult Learning, 12, pp. 9-10 (2001)

23. E.D. Patarkin, Social Interaction and Network learning 2.0, Moscow:Modern technologies in education and culture, p. 176 (2009)

24. E.V. Vasilevskaya, Network mechanisms of development of professional competences of teachers, Continuous pedagogic education.RU, № 5, p. 28 (2013)

25. S.A. Dyatlov, A.Yu. Khanukhova, The specific features of human capital reproduction system transformation in digital economy, Tribune of Saint Petersburg state university, № 2 (116), pp. 14-17 (2019)

26. J.T. MacGregor, What Is Collaborative Learning? National Center on Postsecondary Teaching, Learning, and Assessment at Pennsylvania State University (1992)

27. A.G. Asmolov, Complicated person as a challenge to Pedagogy of Opportunities, Pedagogic Search in Povolzhskiy region, № 1 (23), pp. 13-19 (2018)

28. E. Lazarou, E. Smirnova, N. Vatolkina, M. Dascalu, Preparation of PhD Students for Engineering Disciplines Teaching, Communications in Computer and Information ScienceVolume 1084, pp. 351-365 (2019)

29. V. Mayorova, D. Grishko, V. Leonov, New educational tools to encourage high-school students' activity in stem, Advances in Space Research, Vol.61, Issue 1, 1 January 2018, pp. 457-465 (2018) 
30. N.A. Yegina, A.V. Djuldjanova, O.V. Komarova, N.V. Timoshina, Social transformation in conditions of digital economy: challenges, threats and prospects, Finansovaya Econmika (Financial Economics), № 7, pp. 1703-1705 (2019)

31. N. Vatolkina, O. Fedotkina, International strategic university partnership: Interaction models, Vysshee Obrazovanie v Rossii, Vol. 27. Issue 6, pp.113-119 (2018)

32. E. Zemskova, Sharing as a reflection of customer values in digital economy, Scientific Journal of ITMO University, Series: Economy and Environmental Management, № 3, pp. 17-27 (2019) 